\title{
Self-Compassion and Empathy as Predictors of Happiness among Late Adolescents
}

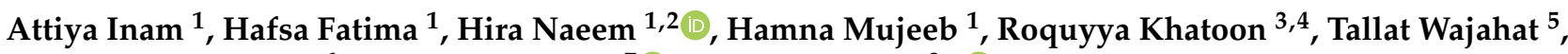 \\ Liviu Catalin Andrei ${ }^{6}$, Slađana Starčević ${ }^{7}$ (i) and Farooq Sher $8, *$ (i)
}

1 Department of Human Development and Family Studies, University of Home Economics, Lahore 54660, Pakistan; attiyainam@uhe.edu.pk (A.I.); hafsafatima28@gmail.com (H.F.); hiranaeem2706@gmail.com (H.N.); hamnamujeeb9990@gmail.com (H.M.)

2 International Society of Engineering Science and Technology, Nottingham NG11 8NS, UK

3 Centre for South Asian Studies, University of the Punjab, Lahore 54590, Pakistan; roquyyazafar@gmail.com

4 Civil Services Academy, Lahore 54660, Pakistan

5 Institute of Education and Research School, University of the Punjab, Lahore 54590, Pakistan; zarishhussain1@gmail.com

6 Faculty of Public Administration, National University of Political Studies and Public Administration, 012244 București, Romania; liviucandrei@yahoo.com

7 Department of Economics and Management, FEFA Faculty, Metropolitan University, Bulevar Zorana Đinđića 44, 11070 Belgrade, Serbia; sstarcevic@fefa.edu.rs

8 Department of Engineering, School of Science and Technology, Nottingham Trent University, Nottingham NG11 8NS, UK

* Correspondence: Farooq.Sher@ntu.ac.uk; Tel.: +44-(0)115-84-86679

check for updates

Citation: Inam, Attiya, Hafsa Fatima, Hira Naeem, Hamna Mujeeb, Roquyya Khatoon, Tallat Wajahat, Liviu Catalin Andrei, Slađana Starčević, and Farooq Sher. 2021. Self-Compassion and Empathy as Predictors of Happiness among Late Adolescents. Social Sciences 10: 380. https://doi.org/10.3390/socsci10100380

Academic Editor: Michaela Rogers

Received: 28 July 2021

Accepted: 8 October 2021

Published: 12 October 2021

Publisher's Note: MDPI stays neutral with regard to jurisdictional claims in published maps and institutional affiliations.

Copyright: (C) 2021 by the authors. Licensee MDPI, Basel, Switzerland. This article is an open access article distributed under the terms and conditions of the Creative Commons Attribution (CC BY) license (https:/ / creativecommons.org/licenses/by/ $4.0 /)$.
Abstract: Happiness is a fundamental characteristic of life, helping individuals to become healthy and productive members of society. Pakistan has been ranked as the 67 th happiest country out of 156 countries in the world. Self-compassion (SC) and empathy are considered some of the finest emotions and moral values of human beings leading to a happier life. This is the first study in South Asia that examined self-compassion as a moderator between empathy and happiness. Furthermore, we also determined self-compassion and empathy as predictors of happiness among late adolescents. Data collected from 566 students, selected randomly from different educational institutions in Lahore, suggested that self-compassion $(r=0.273)$ and empathy $(r=0.131)$ had a significant positive relationship with happiness. Self-compassion and empathy both significantly predicted happiness. Male adolescents had slightly higher self-compassion and mindfulness than females. Self-compassion $(F(3,562)=29.74, p=0.000)$ was found to significantly moderate the relationship between empathy and happiness. Self-compassion can be highly beneficial to relate to oneself, specifically for adolescents who are involved in developing their identities and self-worth, and it makes their transition from adolescence to adulthood easy.

Keywords: social science; self-compassion; empathy; happiness; well-being; late adolescent

\section{Introduction}

Adolescence is a challenging time period for the individuals going through this phase; it follows numerous psycho-social and physiological changes (Backes and Bonnie 2019). Researchers identified a decrease in happiness during adolescence (Uusitalo-Malmivaara 2014; Chen 2020). Many adolescents report developing stress during adolescence (Endedijk et al. 2020), which may predict behaviour problems (Juruena 2014) and can increase the risk of psychiatric illness (Sheth et al. 2017). Several studies (Kyoung Hwang and Lee 2018; Mahmoodi et al. 2019) reported an inverse relationship between stress and happiness. As youth is one of the most important parts of the population for any nation because they contribute most to the development of the nation, it is requisite to ensure well-being and proper development during this age group. Thus, it is important to identify factors 
that enhance the well-being of individuals during this time period. For this purpose, the current research explored self-compassion (SC) and empathy as predictors of happiness among adolescents. Self-compassion is a fundamental resource of happiness (persistent and meaningful life) (Barnard and Curry 2012), and empathy is linked positively with both happiness and well-being (Vinayak and Judge 2018).

\subsection{Self-Compassion}

Self-compassion (SC) is defined as "being open to and moved by one's own suffering, experiencing feelings of caring and kindness toward oneself, taking an understanding, non-judgmental attitude toward one's inadequacies and failures, and recognizing that one's experience is part of the common human experience" (Neff 2016). Higher levels of self-compassion are found to be associated with greater positive affect and life satisfaction, whereas it is negatively associated with aggression, perceived stress, rumination, and symptoms of depression and anxiety (MacBeth and Gumley 2012). Self-compassion helps individuals feel calm, cared for, and connected with people, thus promoting happiness (Gilbert 2005). Individuals with higher self-compassion levels reported being happier as compared to less self-compassionate individuals (Smeets et al. 2014). Self-compassion is linked with feelings of competence, connectedness, independence, and self-determination (Magnus et al. 2010), which are fundamental requisites of well-being and happiness. SC works as an emotion regulation strategy that helps people to handle negative emotions with kindness resulting in increased well-being (Neff 2004).

\subsection{Empathy}

One other factor that plays an important role in happiness is empathy. Empathy usually refers to "the ability to understand or share others' feelings and to respond with appropriate emotions" (Baron-Cohen 2011). It has been identified that empathy positively influences emotional well-being (Khajeh Amirhesam and Fatemeh 2014; Bourgault et al. 2015; Choi et al. 2016) and helps individuals to have a positive self-image and to maintain relationships (Chung 2014) that result in the happiness of the individuals. Research states that greater happiness results in improved health (Kushlev et al. 2020), long life (Diener and Chan 2011), life satisfaction (Nemati and Maralani 2016), and better social interactions (Quoidbach et al. 2019). Happiness focuses on "how people themselves feel and evaluate their lives on the whole; it is commonly referred to as subjective well-being because it captures well-being subjectively and comprehensively" (Hendriks and Bartram 2019). Positive psychology directed attention towards the positive constructs such as wellbeing, happiness, personal strengths, wisdom, creativity, imagination, and characteristics of positive experiences. Happiness has been identified as being well and experiencing gratification or as an inborn or satisfying experience (Myers and Diener 1995). Subjective well-being is a scientific term given to various forms of happiness (Diener 2016), which means happiness is a sentiment that shares the constructiveness of other positive measures causing subjective well-being.

\subsection{Gender and Institution Type in Regards to Study Variables}

The postulation that individual differences such as gender or institution type differ in the ability to be self-compassionate, empathetic (Singer and Lamm 2009), or happy is one of the common stereotypical beliefs still present. As per this stereotypic assumption, females are assumed to be more empathetic and interpersonally oriented than males (Christov-Moore et al. 2014). According to research, one of the possible factors is the cultural expectations regarding gender roles (Löffler and Greitemeyer 2021), which postulates that females are supposed to focus more on others, which is directly related to women being more empathetic (Chen et al. 2014). One other factor is the change in the physiological structure. As they grow older, women have greater levels of oxytocin hormone, which leads to more emotional empathy, whereas men have greater testosterone hormone, which is negatively related to empathy, thus leading to differences in empathy. These factors may 
also lead to gender differences in happiness as well as self-compassion, reporting females to have greater levels of anxiety, depression, and mood disorders as compared to men (Eaton et al. 2012). Similarly, several studies found males to have higher levels of happiness (Ading et al. 2012; Jaisri 2015; Kamthan et al. 2019) as well as self-compassion (Yarnell et al. 2015; Zessin et al. 2015; Muris et al. 2016) as compared to females.

\subsection{Rationale of the Study}

Empathy has a significant relationship with happiness (Meyzari Ali and Bozorgi 2016), which increases emotional as well as psychological well-being (Bourgault et al. 2015; Choi et al. 2016; Morelli et al. 2017). Empathetic individuals reported experiencing less negative affect and greater happiness and well-being (Tkach 2005). By being helpful and kind to others, people feel more connected and satisfied. Empathy helps individuals to have a positive self-image and to maintain relationships (Chung 2014), which result in the happiness of the individuals. The above studies concluded that being compassionate is beneficial for individuals and improves self-esteem and happiness. These all contribute to the general health and development of adolescents. Therefore, it is important to investigate these variables with reference to adolescents in Pakistan.

\subsection{Study Hypotheses}

The present research in this regard intended to test the following hypotheses:

- $\mathrm{H}_{1}$ : Male adolescents are more likely to have high levels of self-compassion, empathy, and happiness than female adolescents.

- $\mathrm{H}_{2}$ : There is likely to be a relationship between self-compassion, empathy, happiness, gender, and institute type of late adolescents.

- $\mathrm{H}_{3}$ : Self-compassion and empathy are likely to predict happiness.

- $\mathrm{H}_{4}$ : Self-compassion is likely to moderate the relationship between empathy and happiness.

- $\mathrm{H}_{5}$ : Self-compassion, empathy, and happiness are likely to be affected by an adolescent's gender and institute type.

\section{Materials and Methods}

The study was quantitative and utilized a cross-sectional research design. The sample included five hundred and sixty-six $(N=566)$ late adolescents (both males and females) within an age range of 17-21 years, who were studying in various public and private educational institutes of Lahore, Pakistan. Sampling was done using probability random sampling.

\subsection{Questionaries}

The study data were collected using three instruments in addition to a demographic information sheet, which was used to obtain the information about the participant's gender and institute type, and a consent form delivered to each participant by hand who were then invited to complete the entire set of tools. Firstly, to measure the SC of participants the Self-Compassion Scale-Short Form (SCS-SF) developed by Raes, Pommier, Neff, and Van Gucht was used (Raes et al. 2011). The SCS-SF is comprised of 12 items. Items were rated on 5-point Likert scale ranging from " 1 ," which means almost never, to " 5 ," which means almost always. A total score was calculated by taking the mean of all 12 items after reverse-scoring negatively worded items (i.e., 1, 9, 4, 8, 11, and 12); higher scores indicated greater self-compassion and vice-versa. The Cronbach alpha reliability of this scale was measured to be 0.52 .

Secondly, the Basic Empathy Scale (BES) developed by Jolliffe and Farrington was used to measure empathy among participants (Jolliffe and Farrington 2006). The BES contains a total of 20-items, out of which 9 measure cognitive empathy and the other 11 measure affective/emotional empathy. It is a 5-point Likert scale in which 1 means "strongly disagree" and 5 means "strongly agree." Averages were computed, after which 
higher scores indicated a high empathy level and vice versa. The Cronbach alpha reliability of this scale was measured to be 0.70. Lastly, the Subjective Happiness Scale (SHS) was used to measure participants' perceived happiness. This scale was developed by Lyubomirsky and Lepper and consists of 4 items (Lyubomirsky and Lepper 1999). Item number 4 was reverse-scored. The scale measured the construct on a 7-point Likert scale. Scoring was cumulative, and a higher score indicated greater happiness. The Cronbach alpha reliability of this scale was measured to be 0.65 .

\subsection{Ethical Approval}

Certain ethical considerations were maintained during this research such as approval of the research proposal, which was received from the University of Home Economics, Lahore, Pakistan. Formal permission was granted by the corresponding authors for all three data collection instruments used in this research. Moreover, consent was also taken from participants, which stated that anonymity of their identity and confidentiality of the provided information was maintained. Participants were not harmed in any way (physically, psychologically) during the conduction of this study.

\subsection{Data Collection and Statistical Analysis}

For the data collection, a total of 6 educational institutes were selected from both public and private sectors. Then, for selecting the $n$ number from the $N$ number such that each participant has an equal chance of being selected, every 3rd student from each class was selected. For this, the researcher asked teachers for the attendance list of the students. These students were informed that they have been selected to participate in research and were asked to sign the consent form if they were willing to participate. As participants were not familiar with the variables of the research, the researcher told them the meaning of the variables and what they are intended to measure. Respondents took 10-15 min to fill all the questionnaires. To obtain more reliable responses, the researcher read all items one by one so that students could understand items and remained focused.

After completing data collection, the researcher examined the responses, and incomplete questionnaires were discarded. The total number of respondents approached was 659, out of which 93 questionnaires were discarded because of incomplete responses, and 566 questionnaires were taken as the final sample of the study. The finalized responses were entered in the "Statistical Package for the Social Sciences (SPSS)" software for data analysis. Firstly, composite scores for all measures were calculated in order to organize multiple correlated variables into meaningful information and to control type 1 error (Song et al. 2013). Descriptive as well as inferential statistics were applied for data analysis. Spearmen product coefficient correlation and regression coefficient were used to assess the relationship among study variables and to find an impact of self-compassion and empathy on happiness. Moreover, one-way ANOVA (for late adolescents' age and institute type) and an independent-sample t-test (for adolescent's gender) was computed to explore the effect of demographic characteristics on the study variables.

\section{Results}

\subsection{Description of Participants}

After discarding 93 questionnaires (as mentioned in the above section), a total of 566 questionnaires were analyzed, and the demographic characteristics showed that $54.1 \%$ of participants were females and $45.9 \%$ were males. The data contained 125 males and 221 girls from all-boys and all-girls institutes, respectively, whereas, 115 boys and 85 girls were from a co-education system.

\subsection{Levels of Self-Compassion, Empathy, and Happiness among Late Adolescents $(N=566)$}

In order to test the 1st study hypothesis, i.e., that male adolescents are likely to have higher levels of self-compassion, empathy, and happiness than female adolescents, we firstly identified levels of all three variables into three categories, i.e., low, moderate, and 
high. For this, the mean scores for overall self-compassion, empathy, and happiness scales were computed. Then, to calculate the cut-off points for all these scales, we subtracted the maximum score of all scales (i.e., " 5 " for SCS-SF and BES and " 7 " for the happiness scale) with a minimum score of these scales (i.e., 1) and divided it by the intended number of categories (i.e., 3). Upon calculation, we obtained the interval value i.e., 1.33 (for SCS-SF and BES) and 2.00 (for the happiness Scale). After that, this interval value was added up to the three categories giving 3.67 (SCS-SF and BES) and 5.00 (happiness) for the moderate level and 5.00 (SCS-SF and BES) and 7.00 (happiness) for the high level. The results of the 1st hypothesis are presented in Figure 1. The findings show that male adolescents had comparatively higher levels of self-compassion (28.8\%) and happiness (51.5\%) but lower levels of empathy (40\%) than female adolescents (19.6, 44.1, and 44.1\% for self-compassion, happiness, and empathy, respectively). It also showed that the overall majority of late adolescents showed moderate levels of self-compassion $(64.6 ; 70.6 \%)$ and empathy $(58.8 ; 54.6 \%)$ but showed higher levels of happiness $(51.5 ; 44.1 \%)$ for males and females, respectively. Thus, the 1st study hypothesis was partially accepted.
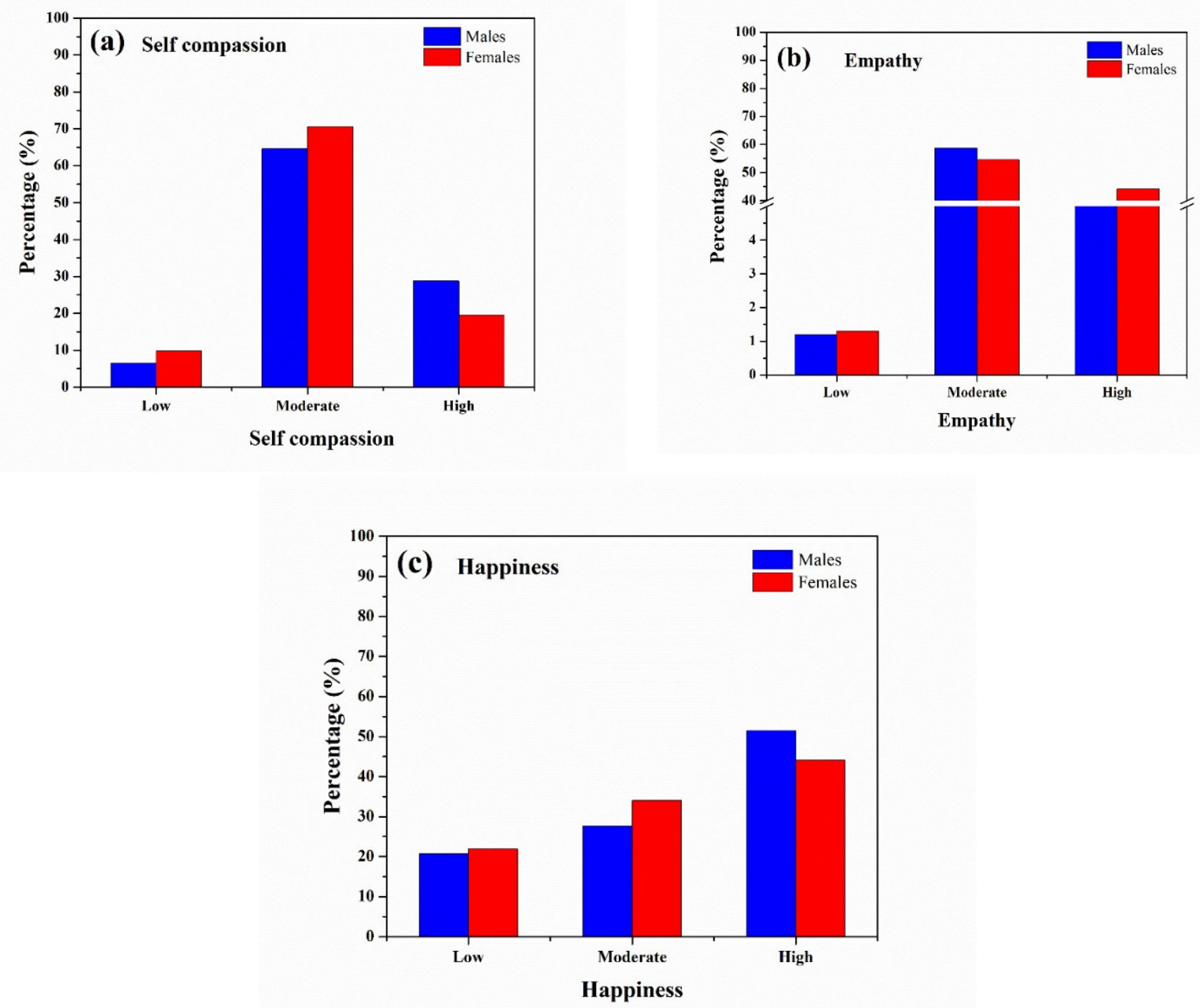

Figure 1. Levels of self-compassion, empathy, and happiness among males and females. 


\subsection{Relationship between Late Adolescents' Gender, Institute Type, Self-Compassion, Empathy, and Happiness}

A Spearman product coefficient correlation was conducted to test the 2nd study hypothesis, i.e., that there is likely to be a relationship between self-compassion, empathy, happiness, and demographic characteristics of late adolescents. For this, firstly, assumptions of the Spearman and Pearson coefficient correlation were checked, and it was found that the data contained some outliers, that it was not normally distributed, and that the majority of the variables showed a monotonic relationship; therefore, Spearman correlation was used. The results are shown in Table 1. The correlation revealed that self-compassion had no significant relationship with overall empathy $(r=0.59)$ but had a significant positive relationship with cognitive empathy $(r=0.147)$ and happiness $(r=0.273)$. It further showed a significant positive relationship of self-compassion with all its positive subscales, i.e., self-kindness $(r=0.512)$, common humanity $(r=0.447)$, and mindfulness $(r=0.495)$, and a significant negative correlation with all its negative subscales, i.e., self-judgment $(r=-0.484)$, isolation $(r=-0.479)$, and over-identification $(r=-0.410)$. Furthermore, empathy revealed no significant relationship with self-compassion but had a significant positive relationship with its own subscales, i.e., cognitive and affective empathy $(r=0.877 ; r=0.791$ respectively) as well as with happiness $(r=0.131)$. Moreover, it was found that self-compassion and mindfulness had a significant negative relationship with gender. Overall empathy, as well as affective empathy, had a significant negative relationship with institute type, whereas gender revealed no relationship with happiness and empathy. Thus, hypothesis 2 was partially accepted.

\subsection{Multiple Linear Regression}

Multiple linear regression was applied to find the prediction of self-compassion and empathy for happiness $\left(\mathrm{H}_{3}\right)$. The results (Table 2) showed that an overall model was significant with $(F(2,563)=35.224 ; p<0.05)$. Furthermore, it indicated that self-compassion $(\beta=0.31, t(565)=8.01, p<0.00)$ and empathy $(\beta=0.08, t(565)=2.17, p<0.03)$ positively predicted happiness among late adolescents, meaning that the higher the level of selfcompassion and empathy the higher was the levels of happiness. Overall, $R^{2}=0.111$ indicated that $11.1 \%$ variance in happiness was explained by self-compassion and empathy among late adolescents. Furthermore, Figure 2 shows the regression line between selfcompassion and happiness as well as empathy and happiness. Thus, 3rd study hypothesis was accepted. 
Table 1. Relationship between self-compassion, empathy, happiness, gender, and institute type of late adolescents $(N=566)$.

\begin{tabular}{|c|c|c|c|c|c|c|c|c|c|c|c|c|c|}
\hline Variables & 1 & 2 & 3 & 4 & 5 & 6 & 7 & 8 & 9 & 10 & 11 & 12 & 13 \\
\hline 1. Gender & - & $-0.522 * *$ & $-0.096^{*}$ & $-0.085^{*}$ & -0.017 & $-0.117^{* *}$ & 0.042 & 0.025 & 0.028 & 0.040 & 0.007 & 0.066 & -0.058 \\
\hline 2. InstituteType & & - & 0.023 & 0.061 & -.058 & 0.070 & 0.058 & -0.045 & -0.020 & $-0.207^{* *}$ & -0.082 & $-0.266^{* *}$ & 0.002 \\
\hline 3. Self.Compassion & & & - & $0.512 * *$ & $0.447^{* *}$ & $0.495^{* *}$ & $-0.484^{* *}$ & $-0.479 * *$ & $-0.410^{* *}$ & 0.059 & $0.147^{* *}$ & -0.021 & 0.273 ** \\
\hline 4. Self.Kindness & & & & - & $0.274^{* *}$ & $0.403^{* *}$ & -0.051 & $0.099 *$ & $0.090 *$ & $0.109^{* *}$ & $0.150 * *$ & 0.051 & $0.238^{* *}$ \\
\hline 5. Common.Humanity & & & & & - & $0.151 * *$ & 0.010 & 0.005 & -0.012 & $0.123^{* *}$ & $0.086^{*}$ & $0.115^{* *}$ & $0.179^{* *}$ \\
\hline 6. Mindfulness & & & & & & - & -0.048 & 0.054 & 0.082 & 0.136 ** & $0.211^{* *}$ & 0.038 & $0.195^{* *}$ \\
\hline 7. Self.Judgment & & & & & & & - & $0.196^{* *}$ & $0.140^{* *}$ & $-0.124^{* *}$ & $-0.175^{* *}$ & -0.053 & $-0.173^{* *}$ \\
\hline 9. Over.Identification & & & & & & & & & - & $0.183^{* *}$ & $0.114^{* *}$ & $0.179^{* *}$ & -0.037 \\
\hline 10. Empathy & & & & & & & & & & - & 0.791 ** & $0.877^{* *}$ & $0.131^{* *}$ \\
\hline 11. Coginitive.Empathy & & & & & & & & & & & - & $0.427^{* *}$ & $0.177^{* *}$ \\
\hline 12. Affective.Empathy & & & & & & & & & & & & - & 0.057 \\
\hline 13. Happiness & & & & & & & & & & & & & - \\
\hline
\end{tabular}

Note. ${ }^{* *} p<0.01 .{ }^{*} p<0.05$. 
Table 2. Self-compassion and empathy as a predictor of happiness among late adolescents $(N=566)$.

\begin{tabular}{lllllll}
\hline & $\boldsymbol{B}$ & $S E$ & $\boldsymbol{\beta}$ & $\boldsymbol{t}$ & $\boldsymbol{p}$ & $\boldsymbol{R}^{2}$ \\
\hline (Constant) & 4.224 & 1.974 & & 2.140 & $0.033^{*}$ & 0.111 \\
Self-Compassion & 0.274 & 0.034 & 0.319 & 8.011 & $0.000^{* * *}$ & \\
Empathy & 0.048 & 0.022 & 0.087 & 2.176 & $0.030^{*}$ & \\
\hline
\end{tabular}

Dependent variable: happiness. Note. ${ }^{* *} p<0.001 .{ }^{*} p<0.05$.
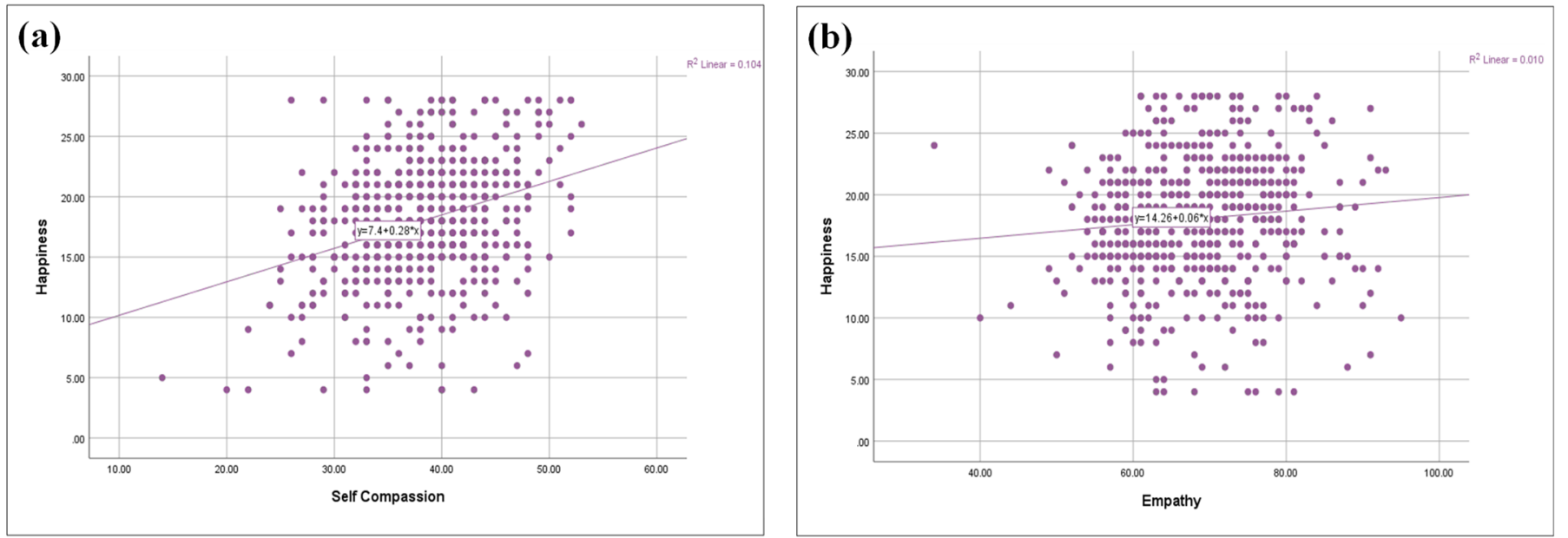

Figure 2. Regression plot of (a) self-compassion and happiness and (b) empathy and happiness.

\subsection{Self-Compassion as Moderator between Empathy and Happiness}

In order to check if self-compassion moderate empathy and happiness, Hayes PROCESS moderation analysis was conducted (Table 3), which revealed that the overall model was significant with $p<0.01$; moreover, $F(3,562)=29.74, p=0.000$ and $R^{2}=0.1370$ determined that $13.7 \%$ of the variance was caused by the predictor. The conceptual model is shown in Figure 3.

Table 3. Self-Compassion as a moderator between empathy and happiness $(N=566)$.

\begin{tabular}{ccccccc}
\hline $\boldsymbol{R}$ & $\boldsymbol{R}^{2}$ & $M S E$ & $\boldsymbol{F}$ & $d f 1$ & $d f 2$ & $p$ \\
\hline 0.3702 & 0.1370 & 21.89 & 29.74 & 3 & 562 & $0.000^{* * *}$ \\
\hline
\end{tabular}

Note. ${ }^{* * *} p<0.001$.

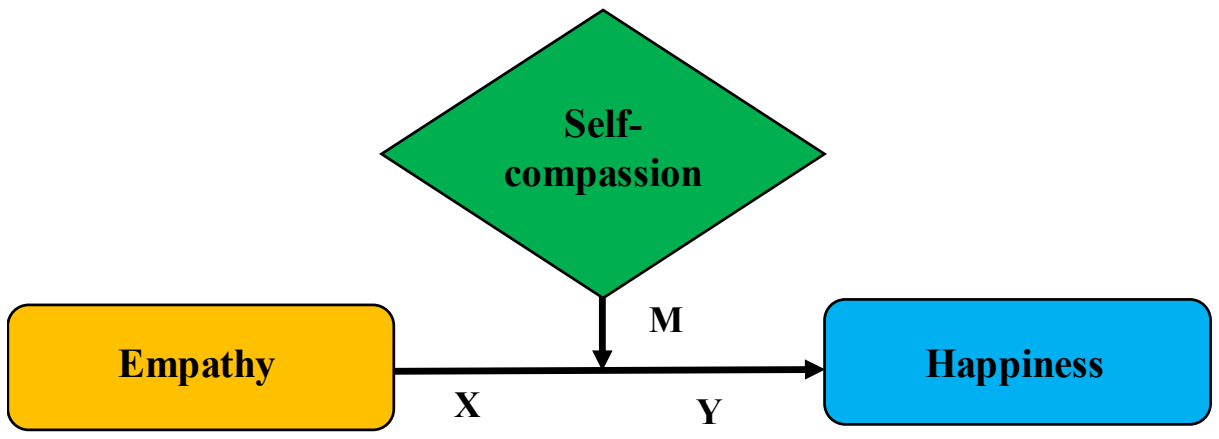

Figure 3. Conceptual model of self-compassion moderation.

Furthermore, we analyzed the effect of empathy on happiness having self-compassion as moderator. The model of self-compassion is shown in Figure 4. The results shown (Table 4) that the regression coefficient for the interaction effect of empathy $\times$ self-compassion was statistically significant $(\beta=0.0145, t(562)=4.099, p<0.0001)$, which revealed that the 
relationship between empathy and happiness was significantly moderated by self-compassion, and the effect of empathy on happiness significantly depended on the effect of self-compassion on happiness.

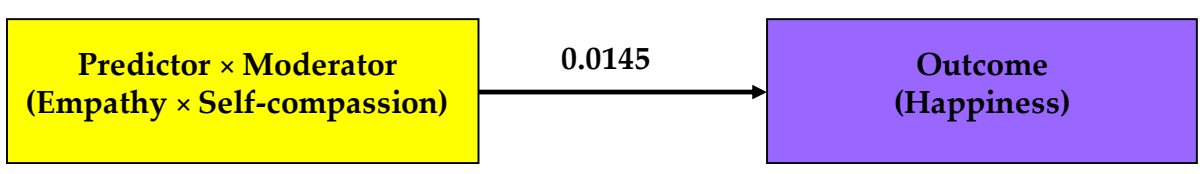

Figure 4. Model of self-compassion moderation.

Table 4. Effect of empathy on happiness and self-compassion as a moderator $(N=566)$.

\begin{tabular}{lcccccc}
\hline & $\boldsymbol{B}$ & $\boldsymbol{S E}$ & $\boldsymbol{t}$ & $\boldsymbol{p}$ & LLCI & ULCI \\
\hline Constant & 42.6302 & 9.5686 & 4.4552 & $<0.000^{* * *}$ & 23.8356 & 61.4249 \\
Empathy $\times$ Self-compassion & 0.0145 & 0.0035 & 4.0995 & $<0.000^{* * *}$ & 0.0076 & 0.0215 \\
\hline & Note. ${ }^{* * *} p<0.001$.
\end{tabular}

Lastly, we checked the change in variance after the interaction effect of empathy and self-compassion on happiness (Table 5). The $\Delta R^{2}=0.0258, p=<0.01$ was statistically significant, which determined that the effect of empathy was significantly dependent on the effect of self-compassion, which, in return, affected individual happiness. Thus, this determined that individuals who are more empathetic and self-compassionate are happier, leading us to accept hypothesis 4 .

Table 5. Interaction effect of empathy and self-compassion on happiness $(N=566)$.

\begin{tabular}{lccccc}
\hline & $\Delta R^{2}$ & $F$ & $d f 1$ & $d f 2$ & $p$ \\
\hline Empathy $\times$ self-compassion & 0.0258 & 16.806 & 1 & 562 & $<0.01^{* *}$ \\
\hline Note. ${ }^{* *} p<0.01$. & & & & &
\end{tabular}

\subsection{Effect of Institute Type and Gender on Self-Compassion, Empathy, and Happiness}

For testing of 5th study hypothesis, i.e., that there are likely to be differences in selfcompassion, empathy, and happiness in relation to adolescents' gender and institute type, we computed a one-way ANOVA (for institute type) and an independent sample t-test (for gender). Table 6 shows that self-compassion, empathy, and happiness had significant mean differences in relation to adolescents' institute type. It also shows that institute type explained small variance in self-compassion $\left(\eta^{2}=0.034\right)$, empathy $\left(\eta^{2}=0.044\right)$, and happiness $\left(\eta^{2}=0.011\right)$.

Table 6. Effect of late adolescents' institute type on self-compassion, empathy, and happiness $(N=566)$.

\begin{tabular}{lllllll}
\hline & $\begin{array}{l}\text { All Girls } \\
(\boldsymbol{n}=\mathbf{2 2 1})\end{array}$ & $\begin{array}{l}\text { All Boys } \\
(\boldsymbol{n}=\mathbf{1 4 5})\end{array}$ & $\begin{array}{l}\text { Co-Education } \\
(\boldsymbol{n}=\mathbf{2 0 0})\end{array}$ & & & \\
& $\boldsymbol{M}((\boldsymbol{S D})$ & $\boldsymbol{M}(\boldsymbol{S D})$ & $\boldsymbol{M}(\boldsymbol{S D})$ & $\boldsymbol{F}$ & $\boldsymbol{p}$ & $\boldsymbol{\eta}^{2}$ \\
\hline Self-compassion & $37.63(5.73)$ & $40.22(5.78)$ & $37.93(5.72)$ & 9.88 & $0.000^{* * *}$ & 0.034 \\
Empathy & $70.68(9.45)$ & $68.99(8.31)$ & $66.29(8.63)$ & 12.93 & $0.000^{* * *}$ & 0.044 \\
Happiness & $17.76(5.06)$ & $18.94(5.23)$ & $17.72(4.76)$ & 3.10 & $0.045^{*}$ & 0.011 \\
\hline Note. ${ }^{* * *} p<0.001 .^{*} p<0.05$. & & & & &
\end{tabular}

Then, post hoc analysis (LSD) was conducted to explore which institute type results in more self-compassion, empathy, and happiness (Table 7). The results of LSD revealed that participants from all-boys institutions $(M=40.22$; $S D=5.78)$ were more self-compassionate than participants from all-girls $(M=37.63 ; S D=5.73)$ and co-education 
institutions $(M=37.93 ; S D=5.72)$. Participants from all-girls $(M=70.68 ; S D=9.45)$ and all-boys $(M=68.99 ; S D=8.31)$ institutions were more empathetic than participants from co-education institutes $(M=66.29 ; S D=8.63)$. Moreover, participants of all-boys institutes $(M=18.94 ; S D=5.23)$ were happier than participants of all-girls $(M=17.76 ; S D=5.06)$ and co-education $(M=17.72 ; S D=4.76)$ institutes. The graphical presentation of this has also been shown in Figure 5.

Table 7. Post hoc analysis (LSD) of late adolescents' self-compassion, empathy, and happiness with institute type $(N=566)$.

\begin{tabular}{lllll}
\hline & $\begin{array}{l}\text { Institute Type } \\
\text { Group I }\end{array}$ & $\begin{array}{l}\text { Institute Type } \\
\text { Group J }\end{array}$ & $\begin{array}{l}\text { Mean } \\
\text { Difference I-J }\end{array}$ & $p$ \\
\hline \multirow{2}{*}{ Self-compassion } & All Boys & All Girls & $2.58268^{*}$ & $0.000^{* * *}$ \\
& All Girls & Co-Education & $2.28569^{*}$ & $0.000^{* * *}$ \\
Empathy & All Boys & Co-Education & $4.39278^{*}$ & $0.000^{* * *}$ \\
Happiness & All Boys & All Girls & $1.18465^{*}$ & $0.006^{* *}$ \\
\hline
\end{tabular}
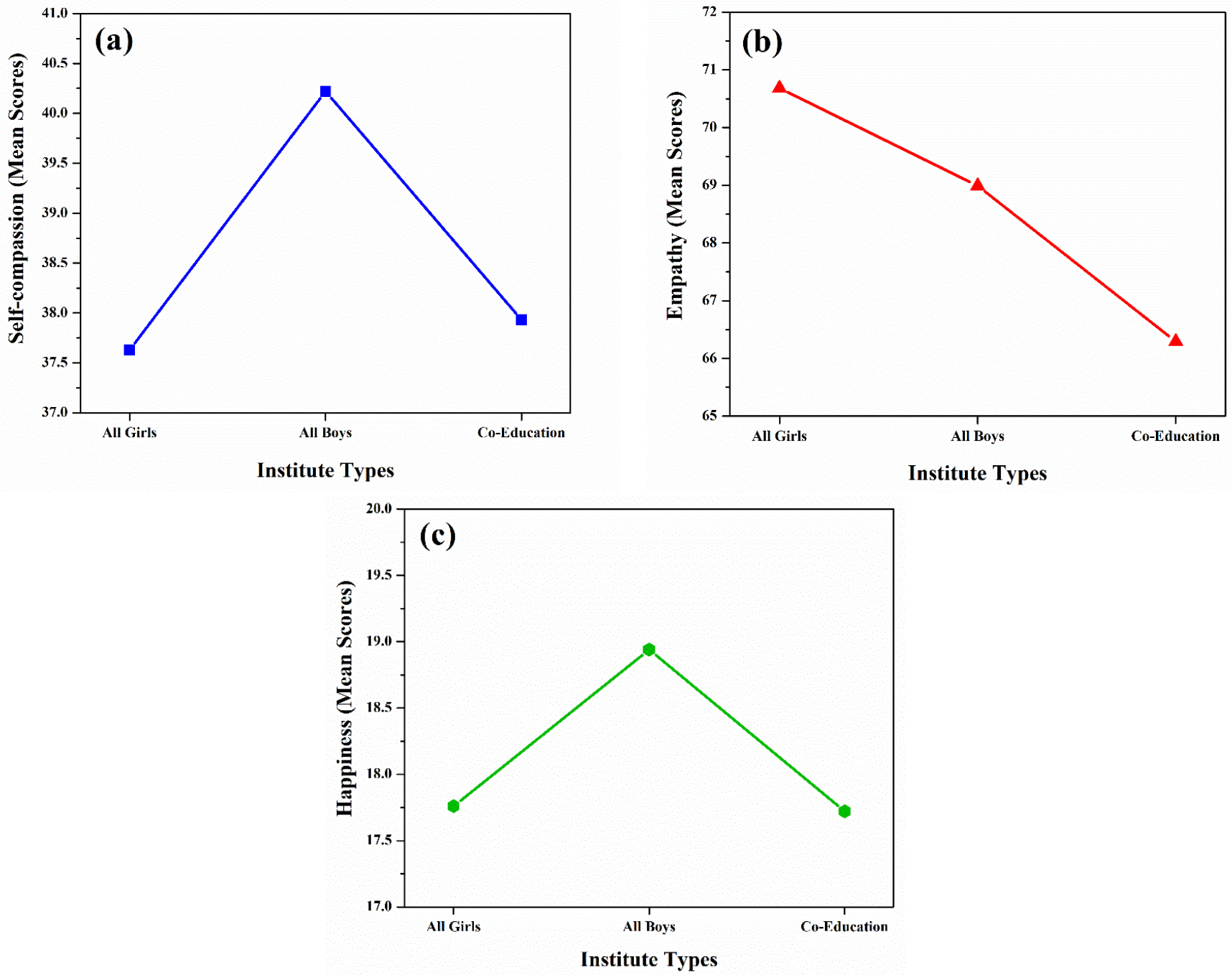

Figure 5. Comparison of (a) self-compassion, (b) empathy, and (c) happiness among adolescents from different types of institutes. 
Furthermore, Table 8 shows that male adolescents were more self-compassionate than female adolescents. However, no significant differences were found in adolescents' empathy and happiness in relation to their gender. Moreover, the value of Cohen's d shows that gender explained a small variance in self-compassion $(d=0.20)$, whereas it had a trivial effect on empathy $(d=0.10)$ and happiness $(d=0.12)$. Thus, we partially accepted hypothesis 5 .

Table 8. Effect of late adolescents' gender on self-compassion, empathy, and happiness $(N=566)$.

\begin{tabular}{|c|c|c|c|c|c|c|}
\hline & $\begin{array}{l}\text { Male } \\
(n=260)\end{array}$ & $\begin{array}{l}\text { Female } \\
(n=306)\end{array}$ & & & & \\
\hline & $M(S D)$ & $M(S D)$ & $t$ & $d f$ & $p$ & Cohen's $d$ \\
\hline Self-compassion & $\begin{array}{l}39.05 \\
(5.97)\end{array}$ & $\begin{array}{l}37.85 \\
(5.67)\end{array}$ & 2.437 & 564 & $0.015^{* *}$ & 0.20 \\
\hline Empathy & $\begin{array}{l}68.18 \\
(8.32)\end{array}$ & $\begin{array}{l}69.14 \\
(9.65)\end{array}$ & -1.250 & 564 & 0.212 & 0.10 \\
\hline Happiness & $\begin{array}{l}18.38 \\
(5.16)\end{array}$ & $\begin{array}{l}17.76 \\
(4.89)\end{array}$ & 1.457 & 564 & 0.146 & 0.12 \\
\hline
\end{tabular}

\section{Discussion}

Firstly, the current study found that male adolescents had higher levels of selfcompassion and happiness but lower levels of empathy than female adolescents. Past studies reported mixed findings regarding levels of self-compassion and empathy, but analogous outcomes regarding levels of happiness among adolescents have been discovered. Researchers found similar results reporting low self-compassion (Yarnell et al. 2015) and well-being (happiness) (Bluth and Blanton 2015) in females than males. However, Muris and colleagues observed no differences in self-compassion between both genders (Muris et al. 2016). Similarly, researchers also reported a high score of empathy in young females as compared to young males (Garaigordobil et al. 2009). The current study found male adolescents to be happier than female adolescents. Similar results have been found in a previous study that found girls having lower satisfaction with life than boys (Moksnes and Espnes 2013). Similarly, several researchers found males to have higher levels of happiness as compared to females (Ading et al. 2012; Jaisri 2015; Kamthan et al. 2019). However, a study done by Sharma and colleagues found contrasting results reporting females having higher levels of happiness than males (Sharma and Gulati 2015).

This conflict in the findings may be the result of the difference in the sample as the present study explored happiness only among late adolescents, while the studies in contrast had samples with different age groups. Research suggests that such gender differences may be due to cultural expectations (Löffler and Greitemeyer 2021) or physiological structure (Chen et al. 2014). The current study discovered a non-significant association between self-compassion and empathy. These results are in line with the previous study done by Wei, which concluded similar results (Wei et al. 2011). However, some studies found contrasting results and detected a significant association between self-compassion and other focused concerns (empathetic concern) (Daltry et al. 2018). Moreover, the results revealed a significant positive relationship as well as the prediction of both self-compassion and empathy with happiness among adolescents. These outcomes are in line with prior studies on the prediction of happiness by self-compassion that found it to be a predictor of happiness and wellbeing (Barnard and Curry 2012). Another study evaluated the predictive role of self-compassion on happiness among students and detected a significant correlation between aspects of SC and found that it predicts happiness in people (Akin and Akin 2014).

Furthermore, the current study also found empathy as a predictor of happiness. Former researchers also discovered identical results. A study done by Vinayak and colleagues assessed the prediction of psychological well-being (PWB) by resilience and empathy among adolescents (Vinayak and Judge 2018) and found resilience and empathy to be 
predictors of well-being among girls; whereas, for boys, only resilience was found to be a predictor of PWB. A study purported to explore the relationship between empathy, coping strategies, and the well-being of Spanish students concluded that understanding others emotions (affective empathy) and state of mind (cognitive empathy) as well as accepting one's own emotions (self-compassion) improve well-being (Carnicer and Calderón 2014). Another study investigated the level to which the Interpersonal Reactivity Index (a measure of empathy) sub-scales predicted psychological well-being in Japanese students and concluded that a component of empathy (perspective taking) enhances psychological well-being (Choi et al. 2016).

Furthermore, the present study discovered that self-compassion significantly moderated the relationship between empathy and happiness. No such evidence was found from previous literature, as, to the researcher's knowledge, to date no such study has been reported that evaluated SC as a moderator between empathy and happiness. However, several studies have evaluated SC as a moderator (Ferreira et al. 2014; Kelly et al. 2014; Homan and Tylka 2015). The effect of SC on empathy has also been well explored, and a significant association between SC and other focused concerns (empathetic concern) has been detected (Neff and Pommier 2013). A study that examined the association between SC and empathy among students found a significant association between both variables (Daltry et al. 2018). As the results of these studies indicate a positive effect of SC on empathy, which in turn increases happiness, we can conclude that SC positively moderates the empathy-happiness relationship. The study found significant differences in SC among male participants and female participants. Male adolescents had slightly higher self-compassion than female adolescents.

Past researchers have also found females having low self-compassion than males. A meta-analysis intended to identify self-compassion differences among genders concluded women having lower self-compassion than men (Yarnell et al. 2015). Previous studies detected low SC and well-being in elderly females as compared to younger males and females (Bluth and Blanton 2015; Bluth et al. 2017), whereas Muris discovered no differences in SC between both genders (Muris et al. 2016). The current study detected significant differences in self-compassion and empathy related to the institute type of late adolescents. Late adolescents who were studying at all-boys institutes had higher SC than adolescents who were studying at all-girls and co-education institutes. Adolescents from all-girls institutes were more empathetic than adolescents from all-boys and co-education institutes, and adolescents of all-boys institutes were more empathetic than adolescents from coeducation institutes. To the best of the researchers' knowledge, to date there has been no research done on self-compassion, empathy, and happiness that compares it specifically with the institute type of participants.

\section{Limitations and Recommendations}

The study was limited to some facts, such as that this study only included healthy adolescents, and adolescents having any kind of physical or psychological illness were excluded. However, researchers suggested that SC is more needed in individuals who are challenged in any way, so this can be termed as a limitation of this study. Based on the findings of this study, some recommendations are suggested. For instance, the study evaluated the association of SC and empathy with happiness, but maybe this association becomes stronger or weaker with age or over time. It is suggested to conduct a longitudinal study on moderating the role of time, age, and other controlling variables on SC, empathy, and happiness. This study explored SC as a moderator between empathy and happiness. Future researchers are recommended to explore other potential mediators (virtues, character strengths) of the empathy-happiness relationship.

\section{Conclusions}

Self-compassion and empathy are considered amongst the distinctive ethics of humanity. These routes are of vital importance to life. On the basis of findings, the study concludes 
that happiness increases when people understand themselves and give acceptance and care to themselves in critical times (self-compassion) and understand other thoughts and emotions and respond to them kindly (empathy). On the contrary, individuals who are less empathetic and less self-compassionate are more self-judgmental and self-criticizing, which makes them unhappy. Though being able to understand other people's thoughts and emotions (empathy) brings greater happiness, it is highly dependent on being able to understand oneself first (self-compassion). So, the emergence of both self-compassion and empathy must be the priority for parents and teachers to ensure greater happiness, specifically for adolescents who are in their critical developmental period (puberty) or experiencing a transition from adolescence to adulthood.

Author Contributions: Conceptualization, A.I., H.N., H.F., and H.M.; software, H.N., R.K., and S.S.; validation, A.I. and H.F.; formal analysis, A.I. and H.N.; resources, R.K. and F.S.; writing-original draft preparation, A.I., L.C.A., H.N., R.K., and T.W.; writing-review and editing, L.C.A., F.S., T.W., and S.S.; visualization, L.C.A. and F.S.; supervision, A.I. and F.S.; project administration, F.S.; funding acquisition, F.S. All authors have read and agreed to the published version of the manuscript.

Funding: This research received no external funding.

Institutional Review Board Statement: The study was conducted according to the guidelines of the Declaration of Helsinki, and approved by the University of Home Economics, Lahore, Pakistan under reference no. RPCC/2(a).

Informed Consent Statement: Informed consent was obtained from all subjects involved in the study.

Data Availability Statement: Not applicable.

Acknowledgments: The authors are grateful to the respective institutes for the financial support to carry on this research.

Conflicts of Interest: The authors declare no conflict of interest.

\section{References}

Ading, Carmella E., Chua Bee Seok, Shazia Iqbal Hashmi, and Ismail Maakip. 2012. Religion and gender differences in stress, happiness and life satisfaction. Southeast Asia Psychology Journal 1: 46-55.

Akin, Ahmet, and Umran Akin. 2014. An Investigation of the Predictive Role of Self-Compassion on Subjective Happiness in Turkish University Students. Education Sciences E Psychology 32: 59-68.

Backes, Emily P., and Richard J. Bonnie. 2019. The Promise of Adolescence: Realizing Opportunity for All Youth. Washington, DC: National Academies Press (US).

Barnard, Laura K., and John F. Curry. 2012. The relationship of clergy burnout to self-compassion and other personality dimensions. Pastoral Psychology 61: 149-63. [CrossRef]

Baron-Cohen, Simon. 2011. The Science ofEvil.'On Empathy and the Origins of Evil. New York: Basic books.

Bluth, Karen, and Priscilla W. Blanton. 2015. The influence of self-compassion on emotional well-being among early and older adolescent males and females. The Journal of Positive Psychology 10: 219-30. [CrossRef] [PubMed]

Bluth, Karen, Rebecca A. Campo, William S. Futch, and Susan A. Gaylord. 2017. Age and gender differences in the associations of self-compassion and emotional well-being in a large adolescent sample. Journal of Youth and Adolescence 46: 840-53. [CrossRef] [PubMed]

Bourgault, Patricia, Stephan Lavoie, Emilie Paul-Savoie, Maryse Grégoire, Cécile Michaud, Emilie Gosselin, and Celeste C. Johnston. 2015. Relationship between empathy and well-being among emergency nurses. Journal of Emergency Nursing 41: 323-28. [CrossRef] [PubMed]

Carnicer, Josep Gustems, and Caterina Calderón. 2014. Empathy and Coping Strategies as Predictors of Well-being in Spanish University Students. Electronic Journal of Research in Educational Psychology 12: 129-46.

Chen, Ke-Mei. 2020. Subjective poverty, deprivation, and the subjective well-being of children and young people: A multilevel growth curve analysis in Taiwan. Children and Youth Services Review 114: 105045. [CrossRef]

Chen, Wuying, Jiamei Lu, Lianqi Liu, and Wenyi Lin. 2014. Gender differences of empathy. Advances in Psychological Science 22 : 1423. [CrossRef]

Choi, Damee, Natsumi Minote, Takahiro Sekiya, and Shigeki Watanuki. 2016. Relationships between trait empathy and psychological well-being in Japanese university students. Psychology 7: 1240. [CrossRef]

Christov-Moore, Leonardo, Elizabeth A. Simpson, Gino Coudé, Kristina Grigaityte, Marco Iacoboni, and Pier Francesco Ferrari. 2014. Empathy: Gender effects in brain and behavior. Neuroscience E Biobehavioral Reviews 46: 604-27. 
Chung, Myung-Sun. 2014. Pathways between attachment and marital satisfaction: The mediating roles of rumination, empathy, and forgiveness. Personality and Individual Differences 70: 246-51. [CrossRef]

Daltry, Rachel M., Kristin E. Mehr, Lindsay Sauers, and Janelle Silbert. 2018. Examining the Relationship between Empathy for Others and Self-Compassion in College Students. Educational Research and Reviews 13: 617-21.

Diener, ed. 2016. Happiness: The Science of Subjective Well-Being. Noba Textbook Series: Psychology; Champaign: DEF Publishers.

Diener, Ed, and Micaela Y. Chan. 2011. Happy people live longer: Subjective well-being contributes to health and longevity. Applied Psychology: Health and Well-Being 3: 1-43.

Eaton, Nicholas R., Katherine M. Keyes, Robert F. Krueger, Steve Balsis, Andrew E. Skodol, Kristian E. Markon, Bridget F. Grant, and Deborah S. Hasin. 2012. An invariant dimensional liability model of gender differences in mental disorder prevalence: evidence from a national sample. Journal of Abnormal Psychology 121: 282. [CrossRef]

Endedijk, Hinke M., Stefanie A. Nelemans, Remmelt R. Schür, Marco PM Boks, Pol van Lier, Wim Meeus, Susan Branje, and Christiaan H. Vinkers. 2020. The Role of Stress and Mineralocorticoid Receptor Haplotypes in the Development of Symptoms of Depression and Anxiety During Adolescence. Frontiers in Psychiatry 11: 367. [CrossRef]

Ferreira, Cláudia, Marcela Matos, Cristiana Duarte, and José Pinto-Gouveia. 2014. Shame memories and eating psychopathology: The buffering effect of self-compassion. European Eating Disorders Review 22: 487-94. [CrossRef]

Garaigordobil, Maite, Carmen Maganto, José Ignacio Pérez, and Eneko Sansinenea. 2009. Gender differences in socioemotional factors during adolescence and effects of a violence prevention program. Journal of Adolescent Health 44: 468-77. [CrossRef]

Gilbert, Paul. 2005. Social Mentalities: A Biopsychosocial and Evolutionary Approach to Social Relationships. New York: Routledge/Taylor \& Francis Group.

Hendriks, Martijn, and David Bartram. 2019. Bringing Happiness Into the Study of Migration and Its Consequences: What, Why, and How? Journal of Immigrant E Refugee Studies 17: 279-98.

Homan, Kristin J., and Tracy L. Tylka. 2015. Self-compassion moderates body comparison and appearance self-worth's inverse relationships with body appreciation. Body Image 15: 1-7. [CrossRef]

Jaisri, M. 2015. Happiness and Self esteem among College Students. International Journal in Management E Social Science 3: 168-78.

Jolliffe, Darrick, and David P. Farrington. 2006. Development and validation of the Basic Empathy Scale. Journal of Adolescence 29: 589-611. [CrossRef] [PubMed]

Juruena, Mario F. 2014. Early-life stress and HPA axis trigger recurrent adulthood depression. Epilepsy E Behavior 38: 148-59.

Kamthan, Shivam, Saurabh Sharma, Rahul Bansal, Bhawna Pant, Parul Saxena, Shivakshi Chansoria, and Arvind Shukla. 2019. Happiness among second year MBBS students and its correlates using Oxford Happiness Questionnaire. Journal of Oral Biology and Craniofacial Research 9: 190-92. [CrossRef] [PubMed]

Kelly, Allison C., Kiruthiha Vimalakanthan, and Kathryn E. Miller. 2014. Self-compassion moderates the relationship between body mass index and both eating disorder pathology and body image flexibility. Body Image 11: 446-53. [CrossRef]

Khajeh Amirhesam, Baharloo Ghafar, and Soliemani Fatemeh. 2014. The relationship between psychological well-being and empathy quotient. Management Science Letters 4: 1211-14. [CrossRef]

Kushlev, Kostadin, Samantha J. Heintzelman, Lesley D. Lutes, Derrick Wirtz, Jacqueline M. Kanippayoor, Damian Leitner, and Ed Diener. 2020. Does happiness improve health? Evidence from a randomized controlled trial. Psychological Science 31: 807-21. [CrossRef]

Kyoung Hwang, Yeoun, and Chang Seek Lee. 2018. Relationship between stress and happiness in middle school students: Dual mediation effect of growth mindset and self-esteem. Medico-Legal Update 18: 248-53. [CrossRef]

Löffler, Charlotte S., and Tobias Greitemeyer. 2021. Are women the more empathetic gender? The effects of gender role expectations. Current Psychology 2021: 1-12.

Lyubomirsky, Sonja, and Heidi S. Lepper. 1999. A measure of subjective happiness: Preliminary reliability and construct validation. Social Indicators Research 46: 137-55. [CrossRef]

MacBeth, Angus, and Andrew Gumley. 2012. Exploring compassion: A meta-analysis of the association between self-compassion and psychopathology. Clinical Psychology Review 32: 545-52. [CrossRef] [PubMed]

Magnus, Cathy MR, Kent C. Kowalski, and Tara-Leigh F. McHugh. 2010. The role of self-compassion in women's self-determined motives to exercise and exercise-related outcomes. Self and Identity 9: 363-82. [CrossRef]

Mahmoodi, Hassan, Haidar Nadrian, Fahime Javid, Ghadriye Ahmadi, Rojia Kasravi, Masomeh Chavoshi, and Fariba Golmohammadi. 2019. Factors associated with happiness among college students: do academic self-efficacy and stress predict happiness? International Journal of Happiness and Development 5: 14-24. [CrossRef]

Meyzari Ali, Raziyeh, and Zahra Dasht Bozorgi. 2016. The relationship of altruistic behavior, empathetic sense, and social responsibility with happiness among university students. Practice in Clinical Psychology 4: 51-56.

Moksnes, Unni K., and Geir A. Espnes. 2013. Self-esteem and life satisfaction in adolescents-Gender and age as potential moderators. Quality of Life Research 22: 2921-28. [CrossRef] [PubMed]

Morelli, Sylvia A., Desmond C. Ong, Rucha Makati, Matthew O. Jackson, and Jamil Zaki. 2017. Empathy and well-being correlate with centrality in different social networks. Proceedings of the National Academy of Sciences 114: 9843-47. [CrossRef] [PubMed]

Muris, Peter, Cor Meesters, Anna Pierik, and Bo de Kock. 2016. Good for the self: Self-compassion and other self-related constructs in relation to symptoms of anxiety and depression in non-clinical youths. Journal of Child and Family Studies 25: 607-17. [CrossRef]

Myers, David G., and Ed Diener. 1995. Who is happy? Psychological Science 6: 10-19. [CrossRef] 
Neff, Kristin. 2004. Self-compassion and psychological well-being. Constructivism in the Human Sciences 9: 27.

Neff, Kristin D. 2016. The self-compassion scale is a valid and theoretically coherent measure of self-compassion. Mindfulness 7: 264-74. [CrossRef]

Neff, Kristin D., and Elizabeth Pommier. 2013. The relationship between self-compassion and other-focused concern among college undergraduates, community adults, and practicing meditators. Self and Identity 12: 160-76. [CrossRef]

Nemati, Shahrooz, and Farnaz Mehdipour Maralani. 2016. The relationship between life satisfaction and happiness: the mediating role of resiliency. International Journal of Psychological Studies 8: 194-201. [CrossRef]

Quoidbach, Jordi, Maxime Taquet, Martin Desseilles, Yves-Alexandre de Montjoye, and James J. Gross. 2019. Happiness and social behavior. Psychological Science 30: 1111-22. [CrossRef]

Raes, Filip, Elizabeth Pommier, Kristin D. Neff, and Dinska Van Gucht. 2011. Construction and factorial validation of a short form of the self-compassion scale. Clinical Psychology \& Psychotherapy 18: 250-55.

Sharma, Neha, and Jatinder Kaur Gulati. 2015. Gender differences in happiness, self-esteem and personality traits in adolescents living in socio-economic hardship. Adolescence 54: 75.

Sheth, Chandni, Erin McGlade, and Deborah Yurgelun-Todd. 2017. Chronic stress in adolescents and its neurobiological and psychopathological consequences: an RDoC perspective. Chronic Stress 1: 2470547017715645. [CrossRef]

Singer, Tania, and Claus Lamm. 2009. The social neuroscience of empathy. Annals of the New York Academy of Sciences 1156: 81-96. [CrossRef] [PubMed]

Smeets, Elke, Kristin Neff, Hugo Alberts, and Madelon Peters. 2014. Meeting suffering with kindness: Effects of a brief self-compassion intervention for female college students. Journal of Clinical Psychology 70: 794-807. [CrossRef] [PubMed]

Song, Mi-Kyung, Feng-Chang Lin, Sandra E. Ward, and Jason P. Fine. 2013. Composite variables: when and how. Nursing Research 62: 45. [CrossRef] [PubMed]

Tkach, Christopher Terrence. 2005. Unlocking the Treasury of Human Kindness: Enduring Improvements in Mood, Happiness, and SelfEvaluations. Riverside: University of California.

Uusitalo-Malmivaara, Lotta. 2014. Happiness decreases during early adolescence-A study on 12-and 15-year-old finnish students. Psychology 5: 541-55. [CrossRef]

Vinayak, Seema, and Jotika Judge. 2018. Resilience and empathy as predictors of psychological wellbeing among adolescents. International Journal of Health Sciences and Research 8: 192-200.

Wei, Meifen, Kelly Yu-Hsin Liao, Tsun-Yao Ku, and Phillip A. Shaffer. 2011. Attachment, self-compassion, empathy, and subjective well-being among college students and community adults. Journal of Personality 79: 191-221. [CrossRef] [PubMed]

Yarnell, Lisa M., Rose E. Stafford, Kristin D. Neff, Erin D. Reilly, Marissa C. Knox, and Michael Mullarkey. 2015. Meta-analysis of gender differences in self-compassion. Self and Identity 14: 499-520. [CrossRef]

Zessin, Ulli, Oliver Dickhäuser, and Sven Garbade. 2015. The relationship between self-compassion and well-being: A meta-analysis. Applied Psychology: Health and Well-Being 7: 340-64. [CrossRef] [PubMed] 